\title{
Chapter 14 \\ "In Our School We Have Students of All Sorts". Mapping the Space of Elite Education in a Seemingly Egalitarian System
}

\author{
Mikael Börjesson, Donald Broady, and Mikael Palme
}

\section{Introduction}

This contribution is devoted to recurring methodological problems in research on elite education in a country where the existence of elites or elite education for many years was hardly acknowledged. The title, 'In our school we have students of all sorts', echoes an expression frequently heard in our interviews at exclusive study programmes. In such highly selective environments, many students, their parents and teachers, and especially the school principals are eager to expose to the visiting sociologist the fallacy that the institution is an elite establishment. Their attitudes surprise the researcher who has already interviewed an array of obviously highly selected and resource-endowed students and teachers as well as observed interactions and teaching practices seldom found in mass education contexts. Thanks to the depth and breadth of Swedish official statistics, the sociologist furthermore has access to hard facts on this matter, namely indicators on these students' - and their parents' and teachers' - possession of symbolic assets, including those that are highly valued within the educational system and in Swedish society at large. For all levels of the educational system, these statistics comprise information at the level of the individual regarding the attended educational institutions, courses and programmes as well as general and course-specific grades. This data can be combined with information from other official statistical registers on the parents' occupational

\footnotetext{
M. Börjesson $(\bowtie) \cdot$ M. Palme

Sociology of Education and Culture (SEC), Uppsala University, Uppsala, Sweden

e-mail: mikael.borjesson@edu.uu.se

D. Broady

Department of Sociology, Sociology of Education and Culture (SEC),

Uppsala University, Uppsala, Sweden
} 
positions, educational levels and incomes. Statistical information on the backgrounds of teachers is available as well.

From a sociological point of view, the refutation of a social fact that, to the researcher, seems undeniable calls for explanation. The educational system obviously works in a manner that obscures the truth of its social conditions and effects. By contrast, in virtually every country outside of Sweden (apart from the neighbouring Scandinavian countries), it is rather obvious that certain parts of the educational system constitute an elite sector. ${ }^{1}$ However, these reactions of denial are not simply expressions of the spontaneous self-understanding that thrives within the educational sphere, but correspond to objective epistemological obstacles regarding the understanding of elite education in relatively egalitarian countries. Overcoming such obstacles is a first step in the construction of Swedish elite education as a research object.

In this contribution, we focus on epistemological and methodological dimensions of this research, drawing on our various experiences over a number of years. ${ }^{2}$ We will first consider epistemological obstacles to the study of elite education in a country renowned for its egalitarianism and which seem to nurture the perception of an educational universe without elites. Thereafter, we will turn to the question of how to construe elite education as a research object, a task that implies considerations on useful definitions. In particular, the relations between different occupational groups and class fractions as well as between different meanings of elite education need to be clarified. Finally, we draw on a previous but recent analysis of the Swedish field of higher education in order to discuss how we have tried to overcome some of these discussed obstacles.

\section{Epistemological Obstacles}

The study of Swedish elite education has to overcome three major obstacles of epistemological nature: the egalitarian appearance of the educational system, its organisational homogeneity, and the administrative (and non-sociological) definitions of its participants.

\footnotetext{
${ }^{1}$ One can for instance mention the French grandes écoles, the American liberal arts colleges, Ivy Leagues and flagship universities, the Russel group universities and the public schools in England, and the Swiss boarding schools. Cf for example Anne-Catherine Wagner's contribution in this book and van Zanten (2018).

${ }^{2}$ Among recent publications in English, see Börjesson and Broady (2016); Börjesson et al. (2016a, b). Our work was originally (Broady and Palme 1989) much inspired by the ongoing seminal research at Centre de sociologie européenne in Paris (Bourdieu and de Saint Martin 1987; Bourdieu 1987, 1989), and is indebted to recent developments in the same tradition (see for instance Serre and Wagner 2015).
} 


\section{First Obstacle: The Egalitarian Beliefs}

Relatively speaking, Swedish society has, in important respects, been one of the most egalitarian in the world. When it comes to economic equity, Sweden by international comparison went through a period of remarkable development from the 1920s until the 1970s in the direction of egalitarianism, and still today - in spite of the rapid growth of economic inequalities in recent decades - boasts one of the most egalitarian distributions of income and wealth.

For the Swedes, however, the neo-liberal turn in the opposite direction since the 1980s has been dramatic. The differences in income, wealth, housing, and so on within the population have widened, accompanied by profound transformations of government policies and dominant ideologies. The educational system has undergone parallel transitions. Traditionally, education beyond primary school was a concern almost exclusively for the upper echelons of the population, and especially its cultural fractions. During most of the twentieth century, rather successful policies for widening access were implemented (Lindensjö and Lundgren 2000) and the provision of education reached an increasingly larger share of the population (Melldahl 2015).

As far as economic factors go, the educational system still offers more equity than in most other countries. Tuition fees are not allowed at schools or at universities (except for students from outside of the EU/EES area). Swedish students, and students within the EU/EES area, who are admitted to an upper secondary school or higher education institution are entitled to grants and loans to cover most of their living costs.

However, since the late 1980s and early 1990s, the educational system has also undergone rapid transformations, involving processes of marketisation, privatisation and internationalisation. The result is sharpened social differentiation within the educational system, which can also be found in other sectors of Swedish society. While tuition fees are still not permitted, public funding of education from primary to upper secondary level is channelled through vouchers that enable families to engage with a free choice model of selecting schools. On the basis of this voucher system, municipal schools and a rapidly growing portion of private schools compete to attract pupils, with increased social and educational differentiation as a result (Forsberg 2018). Higher education, where privatisation has as yet hardly appeared, is increasingly marked by 'new public management' and 'academic capitalism', with more emphasis put on international excellence. Swedish universities are expected to be attractive and compete for students, researchers and resources on the global higher education market. Nowadays it is also possible to talk about 'elite education' in a non-pejorative sense.

Several traps exist here. First, the perception of the Swedish model as promoting equity and equality might be lagging behind its recent transformations, which means an underestimation of actual social and economic differences; there is the alluring temptation to extrapolate a former, and by comparison more equal, condition of the educational system to its current situation. Second, a related and inverse 
obstacle stems from the increased importance of differentiation and excellence having the effect that self-proclaimed elite status must not be taken at face value. For instance, the term 'university' is not regulated when it comes to the English labelling of Swedish higher education institutions, and many Swedish university colleges use the non-accurate label of 'university' in English. Third, and most importantly, if we aim at sociological explanations and abstain from moral and political judgements, the public debates on whether the current degree of inequality is just or not, or whether it is high or low by international standards, constitute an obstacle to the research on the objectively existing social mechanisms at work in the educational system. The fact that educational inequalities are more pronounced in most other countries does not make it sociologically less relevant to analyse how the Swedish educational system contributes to the production, legitimisation, distribution and consecration of assets of key importance to social differentiation.

\section{Second Obstacle: The Homogenous Outlook}

One aspect of what has been called the 'democratisation' of the educational system in the twentieth century, described above as characterised by a focus on widening participation and expansion of the provision of education, was the continuing administrative homogenisation that peaked in the 1960s and 1970s. In the early 1970s, the comprehensive grundskola for all children up to the age of 15 was implemented everywhere in Sweden, which put an end to the former division between the folkskola for the common people and the läroverk (upper secondary grammar school) for the affluent classes. At the same time, all kinds of upper secondary education were merged to create a single type of school - the gymnasieskola. Furthermore, in 1977, the jumble of diverse tertiary (as well as some upper secondary) educational provision became amalgamated into one single organisation, högskolan, comprised of universities, the newer university colleges and the many institutions providing vocational training (such as for primary school teachers, social workers, technicians, etc.). As a consequence, the number of students in higher education increased by $50 \%$ overnight, and the share of the population with higher education diplomas also expanded significantly, inflating the value of a higher education degree (see Melldahl 2015 for details on these effects). While differences have been acknowledged between institutions, the homogeneity of the organisation of higher education has made the boundaries between elite and mass education less discernible than in most countries. The larger universities in particular have become much more diversified and complex in the structure of their educational offer than they once were. This means that the boundaries between elite and mass education, to an even greater extent, run within rather than between administratively defined institutions. 


\section{Third Obstacle: The Administrative Definitions}

A golden rule of sociological research is to be careful not to base your analyses on vocabulary, definitions, categorisations, etc., produced within the domain under study. In our case, vigilance is called upon towards taken-for-granted definitions of different educational assets. What is spontaneously considered to be the boundaries between, for example, different educational levels, vocational versus theoretical secondary school programs, or advanced versus basic higher education programmes, are pre-notions, generated within the educational system and especially as a result of past and present struggles within administrative and political fields. To break with such pre-notions is an indispensable first step towards sociologically fruitful definitions.

The social or meritocratic differences might be hidden when, as is often the case in the public debate or in less rigorous research, you aggregate educational institutions and programmes in such a way that the distribution of assets becomes blurred. One such example is when the recruitment to upper secondary education is analysed on the basis of a dual division of 'theoretical' and 'vocational' programmes. This aggregation hides the substantial social and meritocratic divide that runs between the two major 'theoretical' study programmes, one in natural science and the other in social science. In fact, the former, much more than the latter, exhibits elite characteristics. Here, there is a concentration of students with both significant inherited resources, especially cultural and educational capital, and acquired assets, such as particularly good grades from compulsory school. Further, looking at their study careers following upper secondary education, having attended the natural science programme is more strongly connected to entry into elite institutions in higher education than having attended any other study programme at this level.

Another risk is that everything that falls outside of the educational system's administratively defined borders tends to become invisible, including less wellknown institutions important to elite formation but seldom noticed in research on elite education. Outside of the university system, one important site for the formation of intellectuals has been Tolkskolan (The Armed Forces Interpreter Academy), an institution at the tertiary level which has trained many men for a variety of elite positions, ranging from business to politics, administration and diplomacy, as well as to journalism and academia. Another example is the diplomat programme at the Ministry of Foreign Affairs, a competitive tertiary programme that admits 20 students each year and that opens the door to careers in diplomacy. For the private sector, the large multinational corporations also have their own trainee programmes, which are little studied, but clearly of significance for careers in business and engineering. The great dynasties of bankers and industrialists have used officer training in the military reserve as a means of elite formation for their sons. Throughout the twentieth century, a crucial vehicle for the reproduction of influential parts of the political and administrative elites, especially connected to the Social Democratic Party, were the popular movements, the folkhögskolor connected to these movements and the labour unions' own training programmes. These are examples of 
educational institutions that historically have been important for the formation of particular elites connected to specific social fields, such as the political field. Another example is the gradual transformation during the last five decades of certain folkhögskolor into a system of preparatory institutions for entry into the fields of cultural production, such as literature, art or music. ${ }^{3}$

\section{Definitions}

Another step in the construction of elite education as a research object is to find more productive concepts and definitions to be used as research tools.

\section{The Need for Multidimensionality}

To explore elite education, social complexity cannot be reduced to one-dimensional scales, ranging from high to low, such as 'upper class', 'middle class' and 'lower class'. This reduction of social differences to one vertical dimension makes the educational strategies of groups with particular assets disappear, additionally rendering the recruitment mechanisms to particular institutions incomprehensible. The university professor in Latin and the estate broker become inseparable when brought together in the same, undifferentiated upper middle class category. In this way, more elaborate analyses of social origin and social positions are called for. Making use of fairly detailed information on individuals' occupations available in the public statistical registers, we have, for our analyses, developed classification schemes that seek to give as much justice as possible to both the volume of social groups' assets and the composition of these assets. We most often distinguish 32 social groups that can be aggregated into fewer groups when the populations are small and again desegregated for specific analytical purposes. In order not to turn gender into a separate individual property artificially disconnected from social origin, we combine gender with social origin, differentiating sons of, for example, veterinarians from daughters of veterinarians, leading to 64 categories in total. We typically apply the same classification scheme to information collected from other, independent sources, such as questionnaires and interviews, with a view to make comparisons possible between different kinds of data.

Further, as elite education comprises the education of different types of elites, who hold varying types of assets, educational capital cannot be measured along a similar one-dimensional, simplified scale, going from low to high. This blurs all

\footnotetext{
${ }^{3}$ As Nylander (2014) shows, two folkhögskolor situated in the countryside in Sweden's most southern region are nowadays the most important sites for formation and consecration of the modern jazz elite, outrivalling the ancient and prestigious Royal College of Music (Kungl. Musikhögskolan i Stockholm).
} 
crucial differences between domains of study and types of institutions. We know, for example, that artists have exceptionally long educational careers, but these individuals pass through very specific institutions which provide particular symbolic capital and give shape to a particular habitus (Gustavsson \& Melldahl, this volume), whereas elite careers in the economic field pass through entirely different educational institutions, as they also do in other countries such as France (see Lebaron, this volume). Moreover, the sociological analysis of elite education needs to separate educational capital in its different forms from other types of inherited or acquired cultural assets, avoiding the transformation of one's educational level into the sole indicator of cultural capital.

\section{Three Definitions of Elite Education: The Meritocratic, the Social and the Functional}

From the point of view of our empirical research, at least three definitions of elite education should be departed from: a meritocratic, a social and a functional (Börjesson et al. 2016b; Börjesson and Broady 2016). The first definition, the meritocratic, takes the educational system's own credentials as the starting point and is perhaps intuitively the most obvious. In the operationalised version used in our studies, elite education in a meritocratic sense is defined as a programme or study track with a large proportion of students with high upper secondary school grades or high scores on the Swedish Scholastic Aptitude Test. Here, the key - and, in most cases, the only - selection instrument is scholarly merits, which makes the Swedish system very different from other national educational systems, especially the American one (cf. Stevens 2007). Other means of selection are seldom applied, except, for example, at music or art schools where the admission process comprises tests of skills or evaluations of portfolios.

The second criterion, the social, relates to the resources that students bring with them from their parental home and their upbringing. In a meritocratic system, social characteristics do not count as a legitimate means of selection. Since educational systems, despite all meritocratic ambitions, are de facto structured to a considerable degree according to students' social origin, admission can be organised with a view to compensate for less privileged students' lack of inherited resources, for example through initiatives such as affirmative action and broadening recruitment. Notwithstanding the effect of such initiatives, from a sociological perspective, elite education is characterised by a large concentration of inherited resources. It functions as a reservoir of different assets - social, cultural, economic and specific symbolic resources - that all students entering into elite institutions or elite study programmes, to varying degrees, may take advantage of. It also implies that the student body tends to share a certain set of beliefs, experiences and values, which facilitates further social and educational endeavours. Nonetheless, a conspicuously homogenous recruitment of privileged students might jeopardise the institution's 
legitimacy. Elite institutions or particular elite programmes within larger institutions in Sweden are forced to exhibit some degree of diversity, preferably of a nature that does not threaten their de facto elite character (see Holmqvist 2018).

Thirdly, elite education might be defined via its capacity to pave the way for elite trajectories, to open doors to elite positions in the educational system, in the labour market, in particular social fields and in social life generally. This we have called a functional criterion. Whether it is regarded statistically, as a probability of success, or qualitatively as the elite institution's capacity to shape the minds and bodies of its students in certain ways, the most elitist institutions and programmes are capable of offering a high likelihood of a prosperous career. The challenge of research design is that the outcome can only be evaluated post factum and with a certain time delay in relation to when the studies were carried out. However, most evidence points in the direction that elite education is a conservative business. The longer the history of being an elite institution, the greater the chances of fulfilling the promise of a prosperous career.

These three criteria, used in the definitions above, often go together. Study tracks that are highly selective in meritocratic terms also tend to attract and form a student body with large inherited resources of different kinds and prepare students for dominant social positions. In spite of these incomplete overlaps between the criteria, the composition of resources depends on (and determines) the position of the track, programme or institution within the overall space of education and its relation to the wider social space and, most importantly, to specific social fields.

In other words, elite education should be defined and studied relationally. The position of a particular elite education track, the force that it exerts on students and its effects on society at large cannot be understood in isolation from the relations that constitute this position, primarily the relations to other educational tracks.

\section{Construction of the Research Object}

With the differences between these three definitions of elite education in mind, we will conclude by providing an example of Swedish elite education as a constructed research object. The empirical analysis is presented in more detail elsewhere (see Börjesson and Broady 2016).

\section{Elite Education as the Top Subdivision of an Educational Space}

We depart from a more straightforward definition of elite education as the top subdivision of an entire educational space, in this case the Swedish field of higher education. With a view to unveil the social structure of the space, we first created the social recruitment profiles of all programmes and courses with more than 100 participants at all Swedish higher education institutions. Based on statistical data at the 
individual level, these profiles consisted of the number of daughters and sons ( $\mathrm{n}=264,000$ students) of all previously mentioned 32 social groups, i.e. 64 categories. Further, we added as supplementary variables information on students' upper secondary study programme, their final grade at this level and their test scores from the Swedish Scholastic Aptitude Test. For the analysis of the resulting matrix, we used correspondence analysis (Le Roux and Rouanet 2004, pp. 23-65).

The graph found below shows the overall structure of the Swedish field of higher education. The first and most influential axis, the horizontal one, separates female students to the left from male students to the right, with a gender neutral space between. The second most important axis, vertical in the graph, is primarily oriented according to the resources the students' parents possess. The volume of the inherited resources, especially the cultural ones, increases as one moves from the bottom to the top of the figure. This hierarchical structure is aligned with the educational resources that the students have accumulated on their own. High grades, high test scores and exclusive degrees from the most prestigious upper secondary programmes, such as the natural science programme, are found at the top of the graph, while low grades, test scores and degrees from vocational upper secondary schools or less prestigious theoretical upper secondary programmes, including the social science programme, are more frequently found towards the bottom of the graph, the dominated part of the field.

The dispersion of the students is determined by their distribution across the educational programmes, courses and institutions in higher education. The educational order corresponds to the gender and social orders in society at large. The field of higher education is most clearly divided according to the first dimension, here representing a gendered opposition - programmes in engineering, technology and natural science (male pole) opposing those in health care, education and culture (female pole), with social science in-between. Institutions and, more broadly, types of institutions are differentiated primarily along the second axis. Traditional, large and broad research universities together with traditional specialised professional institutions are positioned in the upper part of the space, and new university colleges and universities populate the lower part of the space. At a more precise level, it is clear that the educational programmes, and especially the professional programmes, are most crucial for establishing the structure of the field. At the most extreme position at the top of the graph is the medical programme, followed by the law programme, which are the two most clear-cut professional programmes. Shorter and semi-professional programmes define the opposite positions at the bottom of the graph: programmes for preschool teachers and nurses for female students and the shorter engineering programmes for male students.

When the first two axes are taken together, the cloud of the educational programmes and courses at specific higher education institutions and the cloud of the social groups divided by gender form a triangular structure with its base at the bottom in the graph. This implies that the difference between male and female students is greatest within the working class-dominated segment of the system and least pronounced in the segment dominated by the upper middle class. Another way to 
put it is that elite education tends to be less gender differentiated than mass education (Fig. 14.1).

Within this field, the elite subspace is indicated by a trapezoid. It is the part of the space characterised by the highest density of cultural capital (both acquired and inherited), as well as by a strong concentration of other species of capital constitutive to the Swedish field of power: economic, juridical, administrative, political, scientific, artistic and so on. The high concentration of resources in this part of the field is understandable from the viewpoint that there is a close relationship between the elite segment and the most dominant spheres in society. The principal homology between the field of elite education and the field of power as demonstrated by Bourdieu and de Saint Martin (1987) and Bourdieu (1989) is arguably valid also for Sweden; although, there is not, in the Swedish case, as strong of an overlap between the two fields as in France, and, in addition, in Sweden there exists to a larger extent alternative trajectories leading into the field of power (see, for instance, the previous

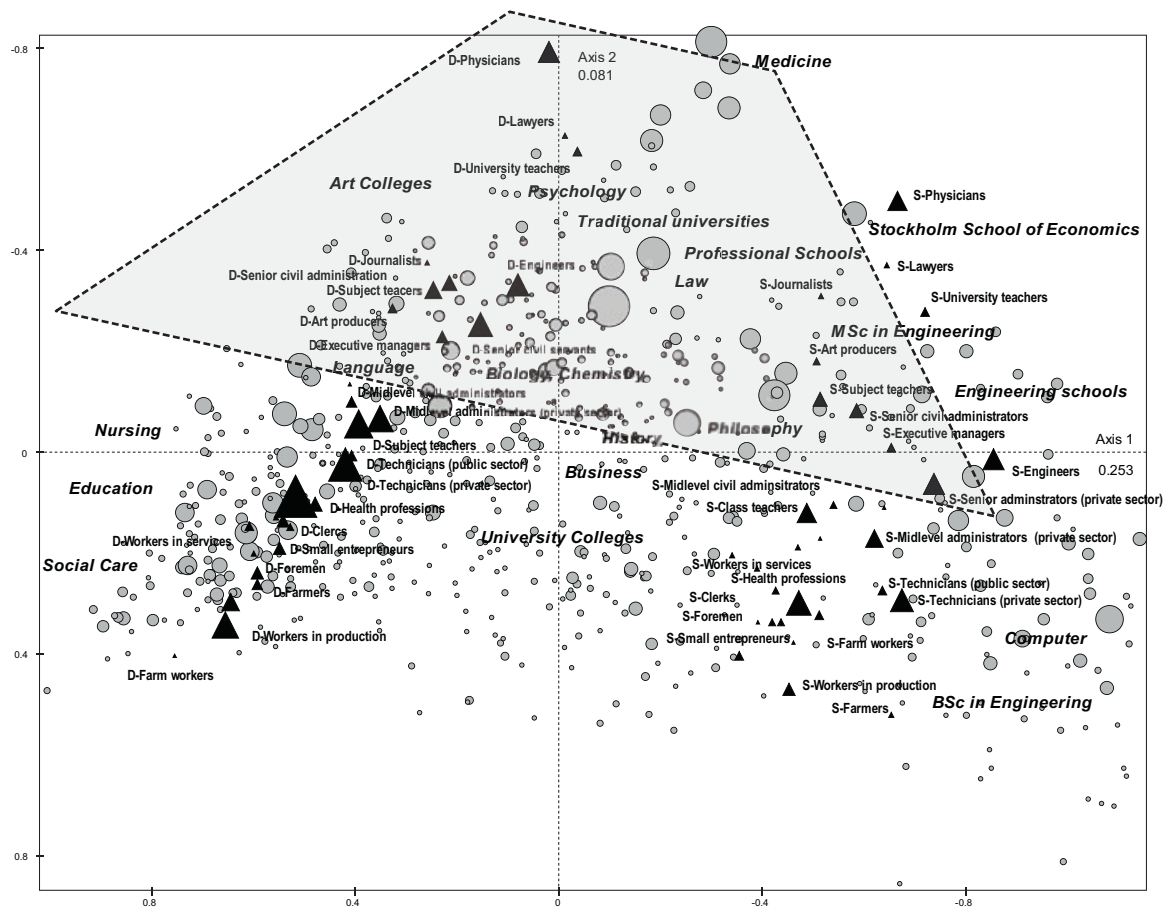

Fig. 14.1 The Swedish field of higher education and the subfield of elite education, autumn 2006. Correspondence Analysis, the plane of axes 1 and 2. 32 categories of social origin, sexes separated Data source: Statistics Sweden Active variables:

$\triangle$ Social origin. $S$ sons, $D$ daughters

Educational programmes/courses offered by higher education institution

The sizes of the triangles and circles are proportional to the number of students in a particular category 
section on alternative elite educational institutions). The analysis reveals that the Swedish sub-space of elite higher education is strongly dominated by a few prestigious longer professional programmes, especially in medicine, law, engineering and social sciences. In fact, students with the highest grades, who in theory have all possibilities open to them, tend to be the most narrow-minded when selecting programmes, only considering the most selective programmes in order to reduce the risk of diluting the value of their educational capital (Lidegran 2009). Furthermore, these programmes are almost without exception located either at one of the few old and prestigious universities or at certain high-ranked profession-oriented schools in the Stockholm area, creating a very distinct geographical concentration of educational resources to the capital region.

From the perspective of the whole field, the subfield of elite education seems less heterogeneous than the rest of the field; gender differences are clearly larger in the bottom half of the field. However, when zooming in on the subfield of elite education, it becomes obvious that there are important differentiations. To start with, keeping to the overall structure of the field, the two most fundamental dimensions, that of gender and social background, do have bearing on the elite subfield. Engineering programmes are opposed to cultural programmes along the first and primarily gendered axis, where male students dominate the former and female students the latter. For the social dimension, the vertical in the graph, the medical programmes stand out as the extreme case, with the most distinct overrepresentation of students from homes with very large volumes of capital, especially cultural and educational capital, combined with an equally strong underrepresentation of students of working class origin. The medical programme is, in this regard, distant from all other programmes, including the other large professional programme, the law programme, which also has a gender-balanced recruitment.

In a complementary study (Börjesson et al. 2016a), we were able to further refine the analysis of elite education in Swedish higher education. In a large survey of 25 elite study programmes including the medical programme, the political science programme, various engineering programmes and programmes in fine arts and acting, at institutions such as the Royal Institute of Technology, Stockholm Institute of Arts, Stockholm School of Economics, and Uppsala University, we distinguished important differences related to symbolic investments in culture, taste and bodyoriented as well as media practices, which primarily differentiated the students according to study programmes and institutions. This indicates that these elite programmes at these institutions very strongly shape students' habitus and embodied capital. In part, the weight of the educational institutional environment in forming students' cultural practices and beliefs is understandable from the perspective that these study programmes, while being fairly gender-balanced, are highly socially selective. However, their particular impact on students' minds and bodies comes from their function, as elite programmes, to prepare students for careers in various social fields where different field-specific symbolic capital is recognised and at stake. This function stretches far beyond classrooms and lecture halls. 


\section{Conclusion}

Our discussion of epistemological obstacles to an understanding of elite education in Sweden and of the need for sociologically fruitful definitions and tools has led us to conclude that a reconstruction of the objective structure of the entire space of Swedish higher education is needed for delimiting the sub-space of elite education and further exploring how particular elite programmes and institutions relate to social fields of power. Here, it is crucial to apply a multidimensional definition of elite education, focusing on both social and meritocratic assets, as well as taking functional aspects into account. With such an approach it becomes apparent that the subspace of elite education is a battleground for the valorisation of different sorts of assets. Furthermore, the subspace of elite higher education in Sweden can, to a large extent, be understood as a relay between on the one hand, the social space (from where the students are originating) and on the other hand, both the field of power in general and particular social fields (the destinations of the students).

\section{References}

Börjesson, M., \& Broady, D. (2016). Elite strategies in a unified system of higher education. The case of Sweden. L'Année sociologique, 66(1), 115-146.

Börjesson, M., Broady, D., Le Roux, B., Lidegran, I., \& Palme, M. (2016a). Cultural capital in the elite subspace of Swedish higher education. Poetics, 56, 15-34.

Börjesson, M., Broady, D., Dalberg, T., \& Lidegran, I. (2016b). Elite education in Sweden: A contradiction in terms? In C. Maxwell \& P. Aggleton (Eds.), Elite education. International perspectives (pp. 92-103). Oxon/New York: Routledge.

Bourdieu, P. (1987). Variations \& invariants. Éléments pour une histoire structurale du champ des grandes écoles. Actes de la recherche en sciences sociales, 70, 3-30.

Bourdieu, P. (1989). La noblesse d'État. Grandes écoles et esprit de corps. Paris: Minuit.

Bourdieu, P., \& de Saint Martin, M. (1987). Agrégation et ségrégation. Le champ des grandes écoles et le champ du pouvoir. Actes de la recherche en sciences sociales, 69, 2-50.

Broady, D., \& Palme, M. (1989). Högskolan som fält och studenternas livsbanor. Paper to the symposium "Självbiografi, kultur och livsform", Esbo, Finland, 10-12 mars 1989.

Forsberg, H. (2018). School competition and social stratification in the deregulated upper secondary school market in Stockholm. British Journal of Sociology of Education, 39(6), 891-907.

Holmqvist, M. (2018). Handels. Maktelitens skola. Stockholm: Atlantis.

Le Roux, B., \& Rouanet, H. (2004). Geometric data analysis, from correspondence analysis to structured data analysis. Dordrecht: Kluwer.

Lidegran, I. (2009). Utbildningskapital. Om hur det alstras, fördelas och förmedlas. Uppsala: Uppsala universitet.

Lindensjö, B., \& Lundgren, U. P. (2000). Utbildningsreformer och politisk styrning. Stockholm: Liber.

Melldahl, A. (2015). Utbildningens värde: Fördelning, avkastning och social reproduktion under 1900-talet. Uppsala: Uppsala universitet.

Nylander, E. (2014). Skolning i jazz. Värde, selektion och studiekarriär vid folkhögskolornas musiklinjer. Linköping: Linköpings universitet. 
Serre, D., \& Wagner, A.-C. (2015). For a relational approach to cultural capital: A concept tested by changes in the French social space. The Sociological Review, 63, 433-450.

Stevens, M. (2007). Creating a class. College admissions and the education of elites. Cambridge, MA: Harvard University Press.

van Zanten, A. (Ed.). (2018). Elites in education. Major themes in education. London: Routledge.

Open Access This chapter is licensed under the terms of the Creative Commons Attribution 4.0 International License (http://creativecommons.org/licenses/by/4.0/), which permits use, sharing, adaptation, distribution and reproduction in any medium or format, as long as you give appropriate credit to the original author(s) and the source, provide a link to the Creative Commons license and indicate if changes were made.

The images or other third party material in this chapter are included in the chapter's Creative Commons license, unless indicated otherwise in a credit line to the material. If material is not included in the chapter's Creative Commons license and your intended use is not permitted by statutory regulation or exceeds the permitted use, you will need to obtain permission directly from the copyright holder.

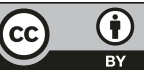

